\title{
GREEN INFORMATION TECHNOLOGY AND SUSTAINABILITY: A CONCEPTUAL TAXONOMY
}

\author{
Asghar Sabbaghi, Indiana University South Bend, sabbaghi@iusb.edu \\ Ganesh Vaidyanathan, Indiana University South Bend, gvaidyan@iusb.edu
}

\begin{abstract}
Several organizations have faced challenges in adopting the usage of information technology in an environment friendly and a sustainable supply chain network. Information technology plays a crucial role in ensuing success of Green supply chain networks. We propose that the Green supply chain management information flow is impacted by both IT governance and Green infrastructure components which in turn are impacted by corporate sustainability. This paper explores various drivers of information technology that enable Green supply chain management and presents a conceptual taxonomy of information technology for sustainability.
\end{abstract}

Keywords: Green IT, Sustainability, Supply Chain, taxonomy, IT governance

\section{INTRODUCTION}

Due to the shift of our economy from paper-based to digital information management and the rapid growth in demand for data processing and storage, sustainability has become one of the major challenges in IT management. Over the last decade, there has been a phenomenal growth in global ecommerce and services, on-line banking and electronic trading, internet communication and entertainment, digitizing medical records for healthcare, and electronic transactions and tracking. For example, the power consumption in US for data center computing and cooling has doubled from 2000 to 2006[13].

Since 2007, when the Environmental Protection Agency (EPA) submitted a report to the US Congress [13] about the expected energy consumption of data centers, Green IT has received growing attention. The overall objective of Green IT is to increase energy efficiency and reduce $\mathrm{CO}_{2}$ emissions [14]. In 2007, government officials estimated energy consumption would double by 2011, requiring the building of 10 additional power plants. The Executive Order 13423 required agencies to reduce energy intensity of $3 \%$ a year or $30 \%$ by the end of fiscal year 2015 . Later, in 2009, the Executive Order 13514 directed agencies to reduce greenhouse gas emissions by 2020 and eliminate or recycle 50 percent of waste by 2015. Other initiatives, such as the Federal Data Center Consolidation Initiative, included a mandated 40 percent reduction in data centers by 2015 . The digital infrastructure supporting the consumption for those requirements has increased in number. This has challenged the IT industry to respond with sustainability and energy efficiency.

Sustainability concerns within the government agencies regarding energy conservation and data center consolidation have been driving the need for the agencies to focus on key technologies that can assist them in achieving a smaller carbon footprint. For example, federal data centers grew from 432 to 1,100 in the last decade [4]. In February 2010, the Office of Management and Budget (OMB) launched the Federal Data Center Consolidation Initiative (FDCCI) to promote the use of Green IT by reducing the overall energy and real estate footprint of government data centers; to reduce the cost of data center hardware, software, and operations; to increase the overall IT security posture of the government; and to increase the use of more efficient computing platforms and technologies [3]. The purpose of this study is to apply the concept of sustainability in the field of IT and examine the drivers behind IT initiatives in organizations. Using these drivers, we will form a conceptual framework that can be used by academicians and practitioners. 


\section{Issues in Information Systems}

Volume 13, Issue 2, pp. 26-32, 2012

\section{SUSTAINABILITY}

Corporate sustainability is defined as meeting the needs of a firm's direct and indirect stakeholders without compromising its ability to meet the needs of future stakeholders [5]. This definition of corporate sustainability considers three dimensions including economic, environmental, and social perspectives. Economic sustainability requires a corporation to manage its resources and economic capital so that it can guarantee cash flow sufficient to ensure liquidity while producing a persistent above average return to their shareholders. The environmental sustainability considers limited natural resources and ecosystem services that are consumed by organizations in various production and operation processes in order to create desired output and economic value. The environmental sustainability may generate undesired output including waste emissions. Organizations do not cause emissions that accumulate in the environment at a rate beyond the capacity of the natural system to absorb and assimilate these emissions and do not engage in activity that degrades eco-system services [5]. The social perspective considers human resources, societal resources, and their capabilities. Given the various stakeholders with sometimes conflicting interest, organizations may not meet the expectations of all stakeholders simultaneously. However, socially sustainable corporations are viewed as those that are seen as fair and trustworthy by all stakeholder groups [9]. Corporate sustainability integrates those three dimensions including economic prosperity, social equity, and environmental resource preservation. Successful organizations need to strike a balance among those three dimensions in order to be sustainable. In this study, we focus on the environmental aspect of sustainability and how this sustainability dimension is impacted by IT. In an organization, the alignment of IT strategy with corporate strategy requires corporate governance and sustainability values to be mapped into Green IT initiatives. Those IT initiatives increase the information flow of Green supply chain management initiatives of organizations.

\section{GREEN IT AND SUSTAINABILITY}

Using Institutional Theory, Chen, Boudreau, and Watson [2] studied to better understand how IT can be leveraged to achieve the three milestones of ecological sustainability including eco-efficiency, eco-equity, and eco-effectiveness. They predicted that organizations can experience mimetic pressures and create strategies to cope with other competing organizations and feel coercive pressures because of governmental laws and regulations.

The term Green IT is defined as the systematic application of sustainability in various processes of IT management in order to reduce related emissions and waste, and to improve energy efficiency [10]. Due to the growing global impact of IT innovation, organizations are increasing their data processing and storage capabilities. The shift from paper to digital information management and data centers has become the way for an organization to function. Green IT includes all the activities and efforts that incorporate ecologically friendly technologies and processes into the entire lifecycle of information and communication technology [7]. Sustainable technology components in IT refers to design, manufacturing, usage, and disposal of information technology components in an efficient and effective method with minimal or no impact on the environment. These components include computers, servers, printers, storage devices, networking, and communication systems. To begin with, manufacturing these components consumes electrical power and generates hazardous waste. Those computer components contain toxic materials and most of them end up in landfills polluting the earth and water. The increased usage of computer components makes this a major environmental concern. The manufacturing further affects the carbon dioxide emissions and impacts the environment. The increase in total electrical energy consumption by those components amplifies the energy consumption results. This is revealed by greenhouse gas emissions as each personal computer in use generates about a ton of carbon dioxide every year [11].

Rhode Island's Bryant University adopted a Green approach to energy management in its data center five years ago, and has experienced campus-wide benefits as a result, including significant decreases in energy costs [1]. It was reported that the University was out of space, power, and cooling capabilities, and thus data center consolidation was definitely on the agenda as was a broader, campus-wide energy efficiency initiative. Working together with the facilities management department, chief financial officer, and president's office, the college's small IT team explored their options and decided to build a brand new data center that was one-third the size of 


\section{Issues in Information Systems}

Volume 13, Issue 2, pp. 26-32, 2012

what they previously had and at the same time bring increased computing and storage capacity by 300 percent. The new data center includes consolidation, centralization, and virtualization as well as space- and energy-efficient and easy to scale up to accommodate the school's growing IT needs. The University installed a software module that enables its IT team to monitor energy consumption across the entire campus and has enjoyed a 15 percent reduction in its energy expenses since rolling out the new data center and the associated equipment and software [1].

Harmon and Auseklis [6] refer to Green IT as the practice of maximizing the efficient use of computing resources to minimize the environmental impact. In their view, the goals of Green IT includes the controlling and reducing a product's environmental footprint by minimizing the use of hazardous materials, energy, water, and other scarce resources, as well as minimizing waste from manufacturing and throughout the supply chain. Green computing practices impact an organization's sustainable IT service strategies and process decisions [6]. In general, Green IT includes the following activities:

- Design for environmental sustainability;

- Green design and manufacturing;

- Energy-efficient power management;

- Practicing and encouraging server virtualization;

- Eco-friendly disposal and recycling;

- Use of renewable energy sources;

- Reducing printing by using electronic file management systems; and

- Use virtual collaboration tools.

In this study, we envision Green IT within the broader context of corporate sustainability values and consider IT as an enabler that would contribute to the three different dimensions of corporate sustainability, namely to achieve economic, environmental, and social values. Green IT strategies strive to achieve enterprise efficiencies through IT procurement and lifecycle management process, recycling and waste disposal strategies and practices, as well as initiatives to reduce energy consumption and carbon footprint through virtualization and other server consolidation techniques, facilities management and other practices. Green IT strategies would also include technologies to gain end user efficiencies through client computing printer rationalization and consolidation, and efficient PCs and peripherals. Furthermore, as a supply chain enabler, IT can help to improve the efficiency and to reduce the energy consumption and the carbon footprint of the organization as a whole. For example, innovative IT initiatives can reduce an organization's carbon footprint by facilitating more efficient and less carbon-intensive work practices teleconferencing instead of flying or commuting, improved supply chain management, IT-enabled energy reduction systems, smart metering, etc. IT tools and techniques such as software-based energy consumption measurement and monitoring tools can help to ensure the business is measuring and monitoring its energy consumption and carbon footprint. In this context, IT would contribute in measuring and monitoring the carbon footprint of the entire organization.

\section{IT GOVERNANCE AND SUSTAINABILITY}

In order to be effective, Green IT initiatives should be rooted in corporate IT strategies, and aligned with corporate sustainability strategies. This requires effective IT governance. As IT infrastructure expands both in size and in complexity, corporations are reaching for better mechanism to assess the role of IT for alignment to their key corporate priorities. IT governance in an organization consists of the leadership, the organizational structures, and the processes that ensure that its IT sustains and extends its strategies and objectives. According to Weil and Ross [15], IT governance encompasses five major decision domains, namely (1) IT principles that consist of high-level decisions about the strategic role of IT in business, (2) IT architecture, an integrated view of technology to meet business needs, (3) IT infrastructure, a physical layout of IT components for coordination and sharing of IT services in order to enable corporate IT capability, (4) application needs and requirements, and (5) prioritization and investment decisions. They have defined six approaches to IT decision making process in order to define the 


\section{Issues in Information Systems}

Volume 13, Issue 2, pp. 26-32, 2012

effectiveness of IT governance in various organizations. Weil and Ross [15] argue that enterprises will design appropriate IT governance to achieve their strategic goals and priorities based on corporate culture and industry. For example, firms focusing on efficiency and profitability may choose to be more centralized in their IT governance for standardization of decisions and processes. On the other hand, companies focusing on innovation and growth may consider decentralization to maximize customer response and minimize constraints on creativity. Some firms may choose a hybrid approach. Large global firms require a hybrid IT governance model to achieve the synergy from the centralized model and the autonomy from the decentralized model [15]. Schmidt and Kolbe (2011) used the contingency theory to define the best configuration of IT governance in general and Green IT governance in particular. They identify strategy, firm size, organizational structure, environmental impact, and IT infusion and IT diffusion as potential contingency factors to determine the ideal Green IT governance.

Corporate sustainability can drive Green IT beyond just energy use and product considerations. It will necessitate the redesign of the IT organization as well [6]. Effective IT governance plays a vital role in driving Green IT initiatives, improving alignment between IT strategies and corporate sustainability. IT governance is a structure of relationships and processes to direct and control organizations to achieve their goals. IT governance is an integral part of organizational governance and it provides the necessary structure that links IT processes, IT resources and information flow to both inter-organizational strategies and intra-organizational value chain. IT governance integrates and institutionalizes the best practices of planning and organizing, acquiring and implementing, delivering and supporting, and monitoring IT performance to ensure that an organization's IT-related technology support its business objectives. It enables the organization to take full advantage of its information, thereby maximizing benefits, capitalizing on opportunities and gaining competitive advantage.

According to a 2011 survey conducted by IT Governance Institute[8], 94\% of respondents considered IT to be important or very important to the delivery of the overall business strategy and vision, and more than $90 \%$ mentioned that the contribution of IT to the business is widely recognized, with value creation of IT investment being of the most important dimensions. And interestingly, about 30 percent of the respondents were planning Green IT initiatives.IT governance enables the existence and sustenance of Green IT in an organization. Both the IT governance and the Green IT enables the organization to take full advantage of its information resources that results in better information flow, thereby maximizing benefits, capitalizing on opportunities, and gaining competitive advantage. Figure 1 illustrates how the Green supply chain management information flow is impacted by both IT governance and Green IT which is impacted by corporate sustainability.

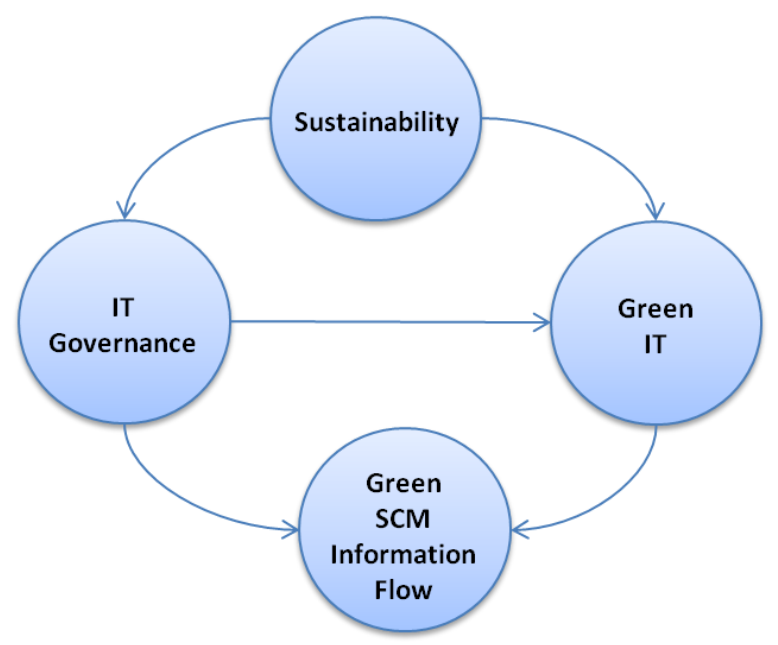

Figure 1 Green Information Flow and Sustainability 


\section{Issues in Information Systems}

Volume 13, Issue 2, pp. 26-32, 2012

In analyzing Green IT, we need to differentiate IT governance and IT management. The former determines who should make decisions and the latter is the process of making and implementing the decision. The responsibility within IT Governance is much broader than IT Management and is focused on performing and transforming the IT in the organization to better meet present and future demands from the business and the customers. IT Governance set the IT principles, IT architecture, IT infrastructure, and business applications in order to map corporate sustainability into Green IT. Thus the alignment of Green IT strategies and corporate sustainability is at the heart of IT governance.

We expand the impact factors of sustainability and Green IT into a conceptual taxonomy of Green information technology for sustainability. There are four tiers to this taxonomy including the Green supply chain management performance, the relational governance, IT components, and the IT information flow as shown in Figure 2. Relational governance may be defined as an informal governance approach where significant relationship specific assets combined with a high level of inter-organizational trust exists in inter-firm exchanges [16]. The taxonomy components are related to each other as shown. The performance of GSCM which is typically cost, quality, delivery, and performance can be taken as a sustainable performance of organizations. The performance is related to the second tier of relational governance which includes IT strategy and IT governance. Relational governance is the economic and sociological phenomena of exchange which includes specific assets, combined with interorganizational trust [16]. The IT governance and the IT strategy are part of the inter-organizational relational governance of organizations.

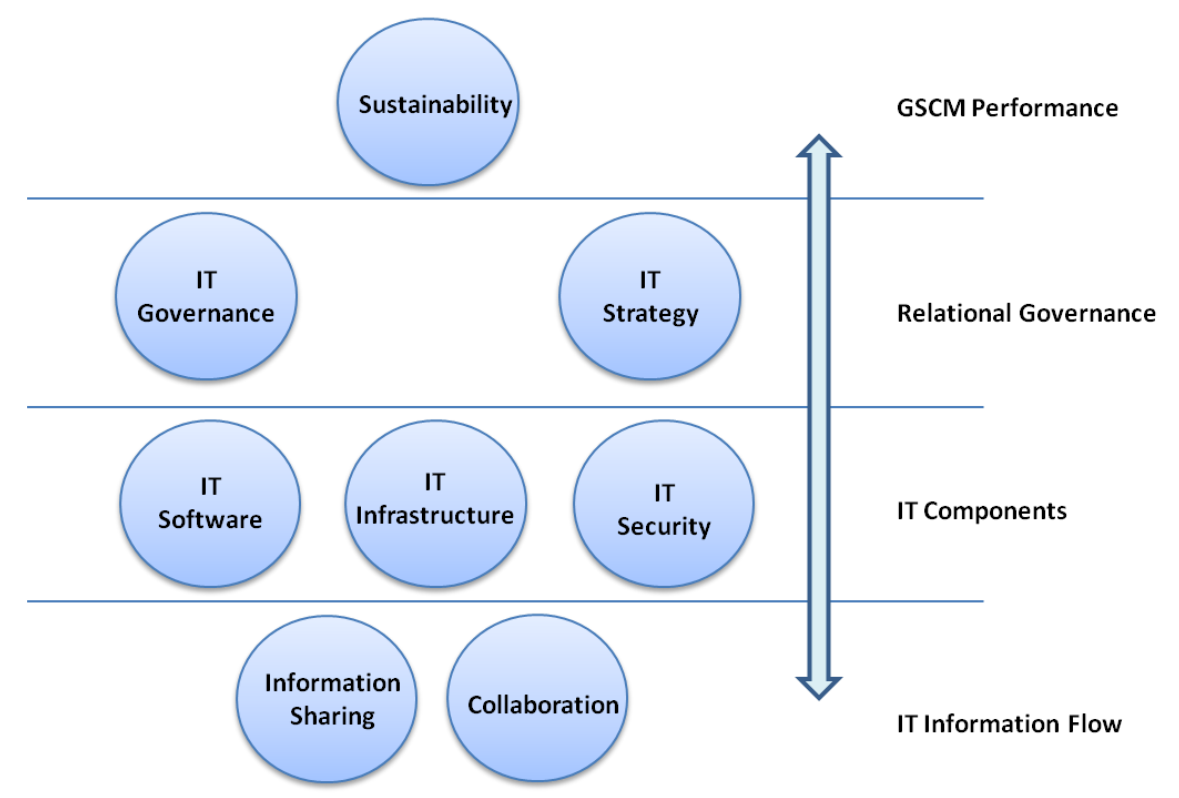

Figure 2 Taxonomy of Green Information Flow for Sustainability

If corporate strategy and governance embraces IT strategy and governance using a common Green ideology then the IT components used within the corporation will reflect the same ideology. Sustainable technology components in IT include computers, servers, printers, storage devices, networking, and communication systems. Apart from these typical components, data center components include storage devices, uninterruptable power supplies, switches, chillers, air conditioners, pumps, cooling towers, generators, batteries, and lighting. Using the components, information flows between supply chain partners. 


\section{Issues in Information Systems}

Volume 13, Issue 2, pp. 26-32, 2012

The amount and type of information that is exchanged between the supply chain partners are important in the sharing and collaboration efforts between organizations. Supply chain networks examine the overall value of information sharing for opportunities to reduce transaction costs. Moreover, information sharing involves security, privacy, and intellectual property

\section{CONCLUSION}

IT resources can play a determinant role in enabling organizations to drive corporate sustainability and Green IT initiatives. However, insufficient attention has been placed on the formal corporate roles, responsibilities, and polices in measuring and reporting sustainability. An effective and efficient IT governance plays a key role in enabling the organization to map corporate strategies into IT strategies and corporate sustainability values into Green IT initiatives. Those Green IT initiatives will strengthen the information flow between the Green supply chain partners. To maximize the Green supply chain value, the information flow between supply chain partners should be efficient and effective. In our view, effective IT governance needs to be part of corporate leadership that would build IT infrastructure, maintain IT architecture (processes, hardware, software, data, and human resources), principles and policies such as regulatory compliance, information security, and risk management as well as allocation of resources (economic, technology, people, and the environment) and IT investment priorities in line with corporate integrity and sustainability values.

This study has established taxonomy for the impacts of Green IT on sustainability. Several research avenues regarding the outcome of sustainability practices can be developed. First, it would be interesting to assess the impact of IT governance on the selection of different environmental technologies. What does collaboration between organizations lead to the selection technologies with respect to sustainability? Second, are there influences of IT governance on information flow and what are the factors of moderation and mediation with regards to sustainability? Third, the influence of different stakeholder groups on operations management remains largely unexplored. We feel that IT governance plays a determinant role in developing effective key performance indicators to measure sustainability in supply chain management as well as in allocation of resources (economic, technology, people, and the environment) in line with corporate sustainability strategies. In our view, considering IT as an enabler of business strategy, IT governance should maintain an effective balance between profitability and innovation for sustainability.

\section{REFERENCES}

1. Campus Technology. (2012). Bryant U cuts energy expenses 15 percent with new data center. Campus Technology IT Trends, February 28, 2012.

2. Chen, A.J.W., Boudreau, M., and Watson, R.T. (2008). Information systems and ecological sustainability. Journal of Systems and Information Technology, 10 (3), 186-201.

3. Ciena (2012). Achieving cost saving and compliance with a Green IT network. Retrieved on May 5, 2012 from www.ciena.com.

4. CIO (2010). Federal data center consolidation initiative. Retrieved on May 2, 2012 from http://www.cio.gov/documents_details.cfm/uid/25A781B7-BDBE-6B59-

F86D3F2751E5CB43/structure/Information\%20Technology/category/Federal\%20Data\%20Center\%20Consolid ation\%20Initiative.

5. Dyllick, T. and Hockerts, K. (2002). Beyond the business case for corporate sustainability. Business Strategy Environment, 11, 130-141.

6. Harmon, R. R., and Auseklis, N. (2009). Sustainable IT services: assessing the impact of Green computing practices. PICMET 2009 Proceedings, August 2-6, 2009, Portland, Oregon, 706-717.

7. Hedwig, M., Malkowski, S., and Neumann, D. (2009). Taming energy costs of large enterprise systems through adaptive provisioning. International Conference on Information Systems (ICIS 2009) Proceedings, Phoenix, AZ. 


\section{Issues in Information Systems}

Volume 13, Issue 2, pp. 26-32, 2012

8. IT Governance Institute. (2011). Global status report on the governance of enterprise IT (GEIT). Retrieved on March 1, 2012 from http://www.isaca.org/Knowledge-Center/Research/Documents/Global-Status-ReportGEIT-10Jan2011-Research.pdf.

9. Kaptein, M., and Wempe, J. (2001). Sustainability management, balancing conflicting economic, environmental, and social corporate responsibilities. Journal of Corporate Citizenship, 1(2), 91-106.

10. Molla, A., Cooper, V.A., and Pittayachawan, S. (2009). IT and eco-sustainability: developing and validating a Green IT readiness model. ICIS 2009 Proceedings, Phoenix, AZ.

11. Murugesan, S. (2008). Harnessing Green IT: principles and practices. IT PRO, January/February, 24-33.

12. Schmidt, N. and Kolbe, L.M. (2011), Towards a Contingency Model for Green IT Governance. Proceedings of 19th European Conference on Information Systems, ECIS 2011, Helsinki, Finland, June 9-11, 2011.

13. US EPA. (2007). Report to Congress on Server and Data Center Energy Efficiency Public Law 109-43. Retrieved on March 1, 2012 from http://www.energystar.gov/ia/partners/prod_development/downloads/ EPA_Report_Exec_Summary_Final.pdf.

14. Watson, R. T., Boudreau, M.C., and Chen, A. J. (2010). Information Systems and Environmentally Sustainable Development: Energy Informatics and New Directions for the IS Community. MIS Quarterly, 34(1), 23-38.

15. Weill, P. \& Ross, J., (2005), A matrix approach to designing IT governance. MIT Sloan Management Review, 46(2), 26-34.

16. Zaheer, A. and Venkatraman, N. (1995). Relational governance as an interorganizational strategy: an empirical test of the role of trust in economic exchange. Strategic Management Journal, 16, 373-392. 